\title{
EL PERJUICIO REPARABLE SOLO POR LA DECLARACIÓN DE NULIDAD \\ COMO ESTÁNDAR DE INVALIDEZ DE LAS ACTUACIONES PROCESALES CIVILES
}

[Damage Compensable Only by the Decree of Nullity Standard to Void Civil Proceedings]

\author{
Felipe Gorigoitía Abbott* \\ Universidad de Valparaíso, Chile
}

\begin{abstract}
RESUMEN
El artículo estudia qué debe entenderse por perjuicio reparable solo por la declaración de nulidad en el proceso civil, en cuanto estándar de invalidez de las actuaciones procesales. Para ello, se aborda el tema de la instrumentalidad de los requisitos procesales como fundamento del principio de trascendencia, para luego analizar las características del perjuicio como estándar de invalidez, a partir de la premisa de que se trata de una opción legislativa antiformalista que busca principalmente resguardar los derechos de los litigantes.

Palabras clave

Nulidad procesal - Perjuicio - Invalidez - Casación
\end{abstract}

\begin{abstract}
This article studies what is to be understood by damage compensable only for the decree of nullity in a civil proceeding, regarding the standard to void civil proceedings. For this, we address the issue of instrumentality of the legal requirements as grounds for the principle of transcendence and then we will analyze the characteristics of damage as standard for nullity based on the premise that this is an antiformalist legislative option seeking to protect the rights of the claimants.

KeYWORDS

Decree nisi - Damage - Nullity Cassation.
\end{abstract}

RECIBIDO el 15 de abril y ACEPTADo el 20 mayo de 2013

* Doctor en Derecho, profesor adjunto de Derecho procesal de la Universidad de Valparaíso. Correo electrónico: felipe.gorigoitia@uv.cl Agradezco a los miembros del departamento de Derecho Procesal de la Universidad de Valparaíso por los comentarios y críticas que han ayudado a mejorar este trabajo, en especial, a los profesores Andrés Peña A. y Claudio Meneses P. 


\section{INTRODUCCIÓN}

La noción de perjuicio es el principal parámetro para determinar la validez de las actuaciones judiciales en nuestro sistema procesal. Se encuentra presente en el Código de Procedimiento Civil desde la modificación introducida por la Ley $\mathrm{N}^{\circ} 7.760$ (de 5 de febrero de 1944), a propósito de la casación en la forma en el artículo 768 , inciso $3^{\circ}$; y en el artículo 83, principal disposición relativa a la nulidad procesal del proceso civil, desde la reforma introducida por la Ley $N^{\circ} 18.705$ (de 24 de mayo de 1988). Además, con algunos matices, se ha recogido en el Código Procesal Penal (artículo 159), en el procedimiento de los tribunales de familia (artículo 25 de la $\mathrm{N}^{\circ} 19.968$ ), en el procedimiento laboral (artículo 429, inciso $2^{\circ} \mathrm{CT}$.) y en el Proyecto de Código Procesal Civil en tramitación en el Congreso Nacional (artículos 117 y 118).

A pesar de su relevancia práctica, no hay mayor reflexión doctrinal acerca de cómo debe entenderse esta noción. Este artículo pretende hacerse cargo de la cuestión, en especial desde la perspectiva del proceso civil. Para ello, en la primera parte, se analiza el principio de trascendencia, desde la perspectiva de la instrumentalidad del derecho procesal. En la segunda parte, se explica la función que cumple en nuestro sistema el perjuicio como principal estándar de invalidez. En la tercera, se realiza una propuesta acerca de cómo debe entenderse el perjuicio en materia procesal, identificando cinco características de él: $i$ ) es una opción antiformalista; ii) solo se aplica en presencia de un defecto procesal; $\mathrm{iii}$ ) supone la privación de derechos para alguno de los litigantes; $i v$ ) requiere de un perjuicio efectivo; y $v$ ) deja a la declaración de nulidad como ultima ratio. En la cuarta parte, y última, se aborda el tema de las nulidades sin perjuicio.

\section{LA INSTRUMENTALIDAD DEL DERECHO PROCESAL Y EL PRINCIPIO DE TRASCENDENCIA}

Aunque con anterioridad, queriendo hacer notar algo similar, ya se había considerado al derecho procesal como un derecho "secundario", “adjetivo", "formal" o "realizador", la denominación de "derecho instrumental" se le debe a Carnelutti, quien postula una categorización de normas entre materiales e instrumentales sosteniendo que mientras las primeras componen inmediatamente un conflicto de intereses, al imponer una obligación y atribuir eventualmente un derecho, las segundas componen el conflicto mediatamente atribuyendo un poder ${ }^{1}$.

${ }^{1}$ Carnelutti, F., Sistema de Derecho procesal civil (Buenos Aires, UTEHA, 1944), I, p. 57. Para hacer gráfica la diferencia, el jurista italiano sostiene que una norma 
La calificación de instrumental del derecho procesal pretende destacar la calidad de medio de esta disciplina respecto de otro derecho que se reconoce como primario o sustantivo. Al respecto, Almagro Nosete afirma que "la naturaleza instrumental del Derecho procesal salta a la vista, pues ninguna pretensión exclusivamente procesal tiene sentido sino en cuanto, directa o indirectamente, tiende a conseguir la aplicación de una norma jurídica a los efectos derivados del reconocimiento de derechos o del establecimiento de obligaciones que trascienden al proceso, como medio de conseguir la efectividad de normas no procesales"2.

El derecho procesal no sirve a finalidades propias, sino es un medio concebido para un fin ajeno a él. Como consecuencia de esto, el cumplimiento de las normas procesales resulta relevante solo en cuanto tutela al derecho sustantivo ${ }^{3}$. No existe un interés propiamente procesal, sino intereses sustantivos protegidos a través del derecho procesal ${ }^{4}$.

El carácter instrumental del derecho procesal hace que los requisitos que pueda establecer una norma de esta índole tengan, al menos en principio, la misma calidad ${ }^{5}$. Aunque normalmente se suele predicar esta respecto de

material diría "si un fundo está rodeado por otros, deberá dejarle paso a la vía pública el fundo colindante a través del que sea más corto el acceso”. En cambio, la norma instrumental dispondría que " $\mathrm{Si}$ un fundo está rodeado por otros, el Juez decidirá cómo debe tener acceso a la vía pública”.

${ }^{2}$ Almagro Nosete, José, en Almagro Nosete, J. - Tomé Paule, J., Instituciones de Derecho procesal (Madrid, Trivium, 1993), I, p. 29.

${ }^{3}$ Montesano, L. - Arieta, G., Diritto processuale civile (2a edición, Torino, Giapichelli 1997), I, p. 272.

${ }^{4}$ Hay autores que niegan el carácter instrumental del Derecho procesal. Se trata de posturas que Dinamarco, C.R., La instrumentalidad del proceso (Lima, Communitas, 2009), p. 306 llama "introspectivas" que "consisten en la visión del sistema procesal en sí mismo y no llega siquiera a cuestionar su función cara al ordenamiento jurídico sustancial”. Es el caso de GoldsChmidT, J., Teoría general del proceso (Barcelona, Labor, 1936), p. 33 ss., quien ve como finalidad del proceso el alcanzar la cosa juzgada; o de Guasp, J., Derecho procesal civil (2a edición, Madrid, Instituto de Estudios Políticos, 1961), p. 34, quien, a partir de la concepción de la satisfacción de pretensiones como esencia de la función procesal, afirma que "la finalidad institucional del proceso no se halla subordinada jurídicamente a ninguna otra, pues la satisfacción de pretensiones es un concepto radicalmente primario desde el punto de vista jurídico". Como consecuencia de esto, el derecho procesal sería un instrumento de los comunes valores jurídicos a los que todo el derecho obedece y se subordina. Ambas son posturas hoy superadas -o, al menos, muy minoritarias- que parten de concepciones del proceso que, más allá de su indudable valor, no lograron trascender a sus autores.

${ }^{5}$ Advierte Dinamarco, C. R., La instrumentalidad del proceso, cit. (n. 4), p. 459, que la instrumentalidad del derecho procesal no es exactamente lo mismo que la de las formas o requisitos de este. No lo es porque operan en planos distintos, una en la relación del derecho procesal con otras disciplinas o situaciones y otra dentro del dere- 
las formas, resulta aplicable en general a toda especie de requisito procesal, concepto más amplio que el primero ${ }^{6}$. Sobre el punto, el Tribunal Constitucional español ha afirmado reiteradamente que estos requisitos "no son valores autónomos con sustantividad propia, sino que solo sirven en la medida en que son instrumentos para conseguir una finalidad legítima"7.

Asumir la calidad instrumental recién mencionada supone un abierto rechazo a asignar valor propio a los requisitos procesales, que es lo que termina por ser formalismo, es decir, a la exigencia de observancia y respeto radical de los requisitos procesales por el solo hecho de ser tales ${ }^{8}$. Si bien las expresiones más básicas y burdas del formalismo se deben entender superadas hace ya bastantes siglos, subsisten formulaciones más sofisticadas que atribuyen a los requisitos procesales cualidades relativas al interés público o a la indisponibilidad. Ellas principalmente se reflejan en una indiscriminada utilización de técnicas como la nulidad o la preclusión como medio de control' ${ }^{9}$, que llevan a que el derecho procesal, en definitiva, fracase en su finalidad de ser un instrumento del derecho material.

Si el proceso no es un fin en sí mismo, ni tampoco lo son las formas y requisitos establecidos en él, se entiende fácilmente que no todo defecto procesal deba necesariamente derivar en la ineficacia del acto, sea a través

cho procesal. Ello, sin embargo, no quita que la segunda de ellas sea una consecuencia necesaria de la primera o, como sostiene BEDAQUE, J., Efectividad del proceso y técnica procesal (Lima, Communitas, 2010), p. 417, "un reflejo interno" de la visión instrumentalista del derecho procesal.

${ }^{6}$ Ortells Ramos, M. - Mascarell Navarro, M. J. - Cámara Ruiz, J., Introducción al Derecho procesal (Cizur Menor [Navarra], Thomson-Aranzadi, 2010), p. 366 ss., incluyen en el concepto de requisito procesal a la aptitud, la voluntad, el objeto, la causa, el lugar, el tiempo y la forma. Con todo, en términos muy amplios, hay autores que entienden a la forma como comprensiva también de los requisitos procesales (así lo hace Bedaque, J., Efectividad del proceso y técnica procesal, cit. (n. 5), p. 113).

${ }^{7}$ Por todas, véase la sentencia del Tribunal Constitucional español 180/1987 (Sala Segunda), de 12 de noviembre, ponente Leguina Villa, FJ $2^{\circ}$. En la misma línea, RAmos MÉndez, F., El sistema procesal español (8a edición Barcelona, Atelier, 2010), p. 240, afirma que: "Como norma general, la regla del procedimiento no puede sustantivarse, es decir, convertirse en fin propio por sí misma. Ello conduce al formalismo, defecto que debe ser firmemente rechazado por convertir en fin lo que no es más que un medio".

${ }^{8}$ La noción de formalismo expuesta es de Bonet NAVArro, Á., Rasgos de la forma y formalismo en el proceso (en defensa de la forma), en Revista de Derecho Procesal Iberoamericana, 5 (1977) 2-3, p. 16.

${ }^{9}$ Es Satta, S., Il formalismo nel processo, en SAtтa, S., Soliloqui e colloqui di un giurista (Padova, Cedam, 1968), p. 58, quien llama la atención acerca del uso que el formalismo puede hacer de figuras como la nulidad o la preclusión, originalmente creadas precisamente para luchas en contra de él. 
de la nulidad o de otra técnica. Esto es lo que tradicionalmente se ha conocido como el "principio de trascendencia" y supone, en célebres palabras de Couture, que "las nulidades no tienen por finalidad satisfacer pruritos formales, sino enmendar los perjuicios efectivos que pudieran surgir de la desviación de los métodos de debate cada vez que esta desviación suponga restricción de las garantías a que tienen derecho los litigantes" ${ }^{10}$. Tal como apunta Alsina, la ineficacia que se sigue de la nulidad debe tener una finalidad práctica, no procediendo la nulidad por la nulidad $\mathrm{misma}^{11}$.

El principio de la trascendencia tiene hoy indudable existencia en nuestro derecho, a partir de su consagración en el inciso primero del artículo $83 \mathrm{CPP}$., pero incluso antes de que se diera una regulación sistemática a la invalidez procesal, normalmente a partir de diversas normas dispersas, ya se había dado por establecido que no todo defecto procesal necesariamente debe implicar la invalidez ${ }^{12}$.

Sentado este principio, la cuestión radica, entonces, en determinar cuándo una irregularidad procesal puede significar la invalidez del acto. La respuesta acerca de este punto es necesariamente particularizada para cada ordenamiento, porque se trata de una opción de carácter político, que trasunta valoraciones acerca de qué se estima digno de protección ${ }^{13}$. Sin perjuicio de esto, se puede constatar que los ordenamientos jurídicos suelen reservar la invalidez para las infracciones que reputan como más graves, dejándose las infracciones más leves sin consecuencias jurídicas o con otras consecuencias menos gravosas. En este sentido, un sistema procesal manifiesta cuáles son las afectaciones que considera más trascendentes dentro de un proceso a través

${ }^{10}$ Couture, E., Fundamentos del Derecho procesal civil (4a edición, B de F, Montevideo, 2002), p. 316.

${ }^{11}$ Alsina, H., Las nulidades en el proceso civil (Buenos Aires, Ediciones Jurídicas Europa-América, 1958), p. 85.

${ }^{12}$ Urrutia Salas, M., Nulidades procesales (Santiago, Imprenta y Encuadernación Víctor Silva, 1928), p. 125; De La Fuente Hernández, N., De los incidentes y de la nulidad procesal, en Las Reformas procesales de la ley 18.705 (Cuadernos de análisis jurídico No 7, Escuela de Derecho Universidad Diego Portales, Santiago, 1988), p. 61; Salas Vivaldi, J., Los incidentes y en especial el de nulidad en el proceso civil, penal y laboral (7a edición, Santiago, Editorial Jurídica de Chile, 2000), p. 86; Pozo Silva, N., De las nulidades procesales (Santiago, ConoSur, 2001), p. 101; Otero Lathrop, M., La nulidad procesal civil, penal y de derecho público (Santiago, Editorial Jurídica de Chile, 2009), p. 86, sostiene lo mismo, respecto de la Corte de Apelaciones de Santiago, aunque advirtiendo que las cortes del resto del país eran excesivamente formalistas.

${ }^{13}$ Por todos, Hernández Galilea, La nueva regulación de la nulidad procesal: el sistema de ineficacia de la LOPJ (Oviedo, Forum 1995), p. 68; CARrasco Poblete, J., La nulidad procesal como técnica protectora de los derechos y garantías de las partes en el Derecho procesal chileno, en Revista de Derecho de la Universidad Católica del Norte, 1 (2011), p. 72. 
de la fijación de estándares de invalidez, que son parámetros que permiten diferenciarlos actos meramente irregulares de aquellos inválidos ${ }^{14}$.

Es importante tener presente que, por grave que se estime la irregularidad, si el acto satisface el estándar legal es válido. Desde esta perspectiva, de alguna manera prevalece en nuestro derecho un principio de especificidad, en la lógica que de que no hay nulidad sin disposición legal que establezca una causal de nulidad, al menos en términos genéricos ${ }^{15}$.

\section{LA OPCIÓN DEL ORDENAMIENTO PROCESAL CIVIL:}

EL PERJUICIO REPARABLE SOLO CON LA DECLARACIÓN DE LA

\section{NULIDAD}

Tal como el ordenamiento procesal español y sus tributarios, el Código de Procedimiento Civil en sus textos originales no incluía un régimen general de la nulidad procesal, limitándose a regular situaciones específicas, a partir de las cuales la doctrina y la jurisprudencia intentaban construir un sistema, con las inseguridades propias de lo que se elabora con poco material. En estas condiciones, no existía un parámetro de validez de origen legal que facilitara el análisis.

Como es bien sabido, esta carencia fue subsanada en el procedimiento civil con la Ley $\mathrm{N}^{\circ} 18.705$, de 24 de mayo de $1988^{16}$. Dentro de ella, se agregó un nuevo artículo 83, en el que se dispuso que "la nulidad procesal podrá ser declarada, de oficio o a petición de parte, en los casos en que la ley expresamente lo disponga y en todos aquellos en que exista un vicio que irrogue a alguna de las partes un perjuicio reparable solo con la declaración de nulidad"17. Se establecen,

${ }^{14}$ Andrés Ciurana, B., La invalidez de las actuaciones en el proceso civil (Valencia, Tirant lo Blanch, 2005), p. 59 ss.

${ }^{15}$ En contra de esta postura, SAlas Vivaldi, J., Los incidentes, cit. (n. 12), p. 83, afirma que "a la legislación chilena le basta el apartamiento de cierta magnitud de las formas legales para que el acto así ejecutado sea susceptible de anularse, sin necesidad de una disposición que lo declare expresamente ineficaz, a menos que la propia ley señale que no es acreedor de tal sanción o lo atribuya un efecto diferente".

${ }^{16}$ Ya se consideró, en su momento, como un avance en la regulación de la nulidad procesal a las inclusiones que sobre ella hizo la Ley $\mathrm{N}^{\circ} 7.760$, en especial al establecer el deber del juez de velar por la regularidad del proceso en el artículo 84 CPC. Sin embargo, el primer intento más o menos sistemático de regulación fue de la ley 18.705. Antes de eso, los intentos de sistematización eran por inducción de los "vestigios de nulidad procesal, desperdigados por el CPC”: SALAS VIVALDI, J., Los principios de especificidad, convalidación, trascendencia y extensión de la nulidad procesal en la legislación chilena, en Revista de Derecho Universidad de Concepción, 151-152 (1970), p. 24.

${ }^{17}$ Los orígenes de la disposición se reconocen en un proyecto de ley presentado en 1969 por el Presidente de la República de esa época, Eduardo Frei Montalva y en un informe sobre el punto del Colegio de Abogado de 1987. El detalle de la historia puede 
entonces, dos grandes hipótesis de nulidad: $i$ ) cuando el legislador expresamente ha contemplado esta consecuencia; y $i$ i) cuando, sin establecerse de manera expresa la nulidad, un vicio causa a una parte un perjuicio que es reparable exclusivamente por la vía de tal declaración.

La referencia al perjuicio en relación con la nulidad, sin embargo, venía de antes. Se había incorporado al Código de Procedimiento Civil por la Ley $\mathrm{N}^{\circ} 7.760$, de 5 de febrero de 1944, que la incluyó como límite del recurso de casación en la forma, en el artículo 768 (hasta entonces, artículo 941), conjuntamente con la falta de influencia en lo dispositivo del fallo. La introducción de esta disposición ya había permitido afirmar el abandono de una intelección formal de la nulidad y el reconocimiento legal del principio de trascendencia ${ }^{18}$.

Se podría decir que el estándar del perjuicio ha gozado de cierto éxito, al menos legislativo, en cuanto se ha juzgado como un parámetro idóneo cada vez que se ha debido tratar el tema en otros cuerpos legales, aunque con algunas diferencias, en especial en lo referente con la consagración expresa de la nulidad como último recurso para la reparación de los defectos procesales. El estándar es prácticamente igual en el Código Procesal Penal que, en su artículo 159, dispone que "solo podrán anularse las actuaciones o diligencias judiciales defectuosas del procedimiento que ocasionaren a los intervinientes un perjuicio reparable únicamente con la declaración de nulidad" y en el Código del Trabajo, que, en su artículo 429 inciso $2^{\circ}$, establece que "la nulidad procesal solo podrá ser decretada si el vicio hubiese ocasionado perjuicio al litigante que la reclama y si no fuese susceptible de ser subsanado por otro medio.

En materia de procedimiento de familia también se consagra el parámetro del perjuicio, pero sin establecerlo expresamente como mecanismo subsidiario. Así, el artículo 25 de la Ley de Tribunales de Familia establece que "solo podrá declararse la nulidad procesal cuando se invocare un vicio que hubiere ocasionado efectivo perjuicio a quien solicitare la declaración". Cosa similar ocurre en el Proyecto de Código Procesal Civil que en el propuesto como artículo 117 dice que son susceptibles de ser anulados "los actos procesales verificados sin cumplir con las formalidades y exigencias que la ley contempla para su eficacia y que han ocasionado perjuicio [...]"19.

verse en Otero Lathrop, M., Derecho procesal civil: Modificaciones a la legislación 1988-2000 (Santiago, Editorial Jurídica de Chile, 2000), pp. 86 ss.

${ }^{18}$ Alessandri Rodríguez, F., Ley $N^{\circ}$. 7.760: reformas introducidas al Código de P. Civil por la ley $N^{\circ} 7.760$ (Santiago, Impr. Otero, 1944), p. 67; SAlas Vivaldi, J., Los principios, cit. (n. 17), p. 27.

${ }^{19}$ Con todo, la constatación es más bien formal, porque el juego de otras normas 


\section{IV. ¿QUÉ DEBE ENTENDERSE POR PERJUICIO REPARABLE SOLO POR LA VÍA DE LA NULIDAD?}

\section{Es una opción antiformalista.}

La decisión de fijar un parámetro de validez que se refiera al perjuicio que causa el defecto procesal a las partes es una opción antiformalista que está en línea con la concepción de los requisitos procesales como meros instrumentos que se explicaba más arriba ${ }^{20}$. En esta especie de parámetro, no es, en principio, relevante el grado de separación que se verifique entre el acto y su modelo normativo, sino la afectación que esa separación produce. Puede ser que una pequeña separación formal cause una afectación relevante, mientras otra formalmente mucho mayor resulte intrascendente ${ }^{21}$.

Un parámetro que se refiera a la afectación en la situación de alguna de las partes se encuentra en línea con la tendencia de entender a la nulidad como una técnica protectora de los valores más preciados de un sistema ${ }^{22}$, que se expresa, por ejemplo, en la Ley de Enjuiciamiento Civil española con el establecimiento de la afectación de las garantías procesales de rango constitucional como principal estándar de invalide $z^{23}$ o la noción italiana de cumplimiento de la finalidad ${ }^{24}$. La diferencia entre los parámetros de

y consideraciones de economía procesal hacen que, incluso sin disposición expresa, se pueda considerar a la nulidad como una técnica siempre residual.

${ }^{20}$ Ya lo entendía así, respecto de la Ley $\mathrm{N}^{\circ}$ 7.760, Alessandri Rodríguez, F., Ley $N^{\circ} 7.760$, cit. (n. 18), 760, p. 66.

${ }^{21}$ Ramos Méndez, F., El sistema procesal español (8a edición, Atelier, Barcelona, 2010), p. 290.

${ }^{22}$ Sobre el punto, Hernández Galilea, La nueva regulación, cit. (n. 13), p. 131 ss.; ANDrÉs Ciurana, B., La invalidez de las actuaciones en el proceso civil, cit. (n. 14), pp. 94 ss.; Carrasco Poblete, J., La nulidad procesal, cit. (n. 13), p. 69 ss.

${ }^{23}$ Se suele reconocer el parámetro general de validez de ella en el artículo 223.3 LEC. y 238.3 LOPJ. (son idénticos), que establece la nulidad "Cuando se prescinda de normas esenciales del procedimiento, siempre que, por esa causa, haya podido producirse indefensión": HERnÁNDEZ GALILEA, La nueva regulación, cit. (n. 13), p. 175 ss.

${ }^{24} \mathrm{El}$ artículo 156 del Codice di Procedura Civile dispone que "Non può essere pronunciata la nullità per non osservanza di forme di alcun atto del processo, se la nullità non e' comminata dalla legge. Puo tuttavia ssere pronunciata quando latto manca dei requisiti formali indispensabili per il raggiungimento dello scopo. La nullità non può mai essere pronunciata, se latto ha raggiunto lo scopo a cui è destinato". Aunque con una relevancia hermenéutica marginal, también se encuentra presente este parámetro en la LEC., en el artículo 225.1 (240.1 LOPJ.), que dispone que: "La nulidad de pleno derecho, en todo caso, y los defectos de forma en los actos procesales que impliquen ausencia de los requisitos indispensables para alcanzar su fin o determinen efectiva indefensión, se harán valer por medio de los recursos legalmente establecidos contra la resolución de que se trate, o por los demás medios que establezcan las leyes procesales". 
esta especie está dada por la manera de determinar aquella afectación, pero coinciden todas en la diferencia cualitativa entre los juicios de irregularidad e invalidez, descartando que un acto meramente irregular se diferencie de uno inválido por sus niveles de separación del modelo que se emplea de referencia.

Aunque hay una clara tendencia a privilegiar la fijación parámetros de validez no formales, existen aún resabios de estándares más formalistas. Estos vienen dados, principalmente, por la noción de defectos esenciales o sustanciales $^{25}$. De acuerdo a este criterio, la nulidad se decretaría cada vez que haya una irregularidad que afecte a ciertos requisitos que son de la esencia del acto, lo que se ha identificado con normas imperativas o vinculadas al orden público ${ }^{26}$. La validez o invalidez de un acto regular no vendría dada por las consecuencias que causa el defecto, sino por el grado de afectación. Si se afecta un requisito accidental del acto, no hay nulidad, aunque haya perjuicio. Por el contrario, si es que se ataca un requisito esencial, el acto sería nulo, aún sin perjuicio.

La esencialidad fue establecida como estándar de validez en el Codice di Procedura Civile italiano de 1856 , generando más críticas que alabanzas ${ }^{27}$. Chiovenda llegó a decir que se trataba de un "campo de infinitas cuestiones"28, por las dificultades que entrañaba en muchos casos determinarla. Esto llevó a que en el Codice de 1942 se eliminara toda referencia a ella, sustituyéndose como estándar por el parámetro del cumplimiento del fin, indicado más arriba.

En el código chilenbo, lo esencial aparece en el artículo 84 CPC., configurado como una excepción que permite plantear un incidente sin afectarse por las normas de preclusión establecidas en la misma disposición. En lo que nos interesa, se establece que un incidente planteado de forma extemporánea debe ser rechazado de plano, a menos que se trate de un incidente de nulidad, caso en el que se debe seguir el plazo de cinco días del artículo 83, inciso $2^{\circ}$ CPC., salvo que se afecte una "circunstancia esencial para la marcha o ritualidad del juicio”, caso en el que el incidente igualmente podría prosperar. En

${ }^{25}$ En realidad, por una forma de entender la esencialidad vinculada con la afectación de normas Eso, sin perjuicio de que en todos los ordenamientos existen nulidades meramente formales. Sobre ellas, véase el apartado V de este trabajo.

${ }^{26}$ MARTín DE LA LeONA, J. M., La nulidad de actuaciones en el proceso civil (2a edición, Madrid, Colex, 1996), p. 191.

${ }^{27} \mathrm{Su}$ artículo 56 decía: "Non può pronunciarsi la nullità di alcun alto di citazione o di altro atto di procedura se la nullità non sia dichiarata dalla legge. Possono tuttavia annullarsi gli alti che manchino degli clementi che ne costituiscono lessenza"

${ }^{28}$ Chiovenda, G., Las formas en la defensa judicial del derecho, en CHiovenda, G., Ensayos de Derecho procesal (Buenos Aires, Ediciones Jurídicas Europa-América, 1949), II, p. 150. 
la referencia a lo esencial se ha visto una remisión a los trámites establecidos como indispensables por los artículos 795 y 800 CPC. ${ }^{29}$.

Sin perjuicio de otros problemas de intelección que pueda generar esta norma, por ejemplo, en lo relativo a la posibilidad de convalidación de determinados defectos, cabe hacer presente que si se entiende de esta manera, la esencialidad termina por desvanecerse como requisito formalista, porque la omisión de los trámites determinados como esenciales generan nulidad, en principio, solo si es que hay un perjuicio ( 768 No 9 CPC., en relación con el inciso penúltimo del mismo artículo ${ }^{30} 31$.

\section{Solo se aplica en presencia de un defecto procesal.}

El control del perjuicio solo se realiza respecto de actos irregulares, es decir, de actos defectuosos. En el Código ello se deriva claramente del artículo 83, cuando se refiere a que la nulidad procesal podrá ser declarada "en todos aquellos casos en los que exista un vicio [...]". Sin vicio no hay posibilidad de declarar la nulidad ${ }^{32}$. En consecuencia, si se hicieran jugar las categorías de regularidad y validez, tendríamos solo tres hipótesis normativamente posibles: $i$ ) actos regulares y válidos; $i i)$ actos irregulares y válidos, que serían aquellos actos defectuosos que no han causado un perjuicio reparable solo por la declaración de nulidad, sea porque no han causado un perjuicio o porque este se puede reparar por una vía diversa a la declaración de nulidad; y iii) actos irregulares e inválidos, que serían aquellos actos defectuosos

${ }^{29}$ De la Fuente Hernández, N., De los incidentes y de la nulidad procesal, cit. (n. 13), p. 63, Otero Lathrop, M., La nulidad procesal, cit. (n. 12), p.107. En contra, en una postura muy fundada pero que no ha tenido repercusión doctrinal posterior, Urrutia Salas, M, Nulidades procesales, cit. (n. 12), pp. 126-127.

${ }^{30}$ Sobre el punto, véase el apartado $\mathrm{V}$ de este trabajo.

${ }^{31}$ Parecido es lo que ocurría con el artículo 69 de nuestro antiguo Código de Procedimiento Penal, según el texto que le dio la Ley $\mathrm{N}^{\circ} 18.857$, de 6 de diciembre de 1989, que disponía que "Solo pueden anularse los actos procesales cuando la violación de las normas que los establecen esté sancionada con la nulidad o se refiera a un acto o trámite declarado esencial por la ley. La interacción de esta disposición con el artículo 71 bis, que establecía que la nulidad se entendía subsanada "cuando, no obstante el vicio de que adolezca el acto, este haya conseguido su fin respecto de todos los interesados" producía el mismo efecto de dejar a la esencialidad como criterio irrelevante. Sobre esto: Tavolari Oliveros, R., Nuevo régimen de la nulidad procesal penal, en El mismo, Estudio de derecho procesal (Valparaíso, Edeval, 1990), p. 213 ss.

${ }^{32}$ Colombo Campbell, J., Los actos procesales (Santiago, Editorial Jurídica de Chile, 1990), II, p. 466; Otero Lathrop, M., La nulidad procesal, cit. (n. 12), p. 59. El término vicio supone una intelección de la nulidad como un elemento intrínseco del acto que ha sido superado por la doctrina, que tiende hoy a ver a esta como una técnica de protección. Sobre esto, véase Carrasco Poblete, J., La nulidad procesal, cit. (n. 13), p. 79. 
que sí causan un perjuicio solo reparable por la declaración de nulidad. La hipótesis normativamente ausente e es la de los actos regulares inválidos, es decir, actos que, a pesar de corresponderse con su modelo, son susceptibles de ser anulados por generar un perjuicio.

Hay solo dos categorías de excepciones a esta última regla. La primera guarda relación con las situaciones de lo que normalmente se conoce como "nulidad por fuerza mayor" y "nulidad por falta de emplazamiento", respectivamente establecidas en los artículos 79 y 80 CPC. Estos casos, absolutamente excepcionales, permiten dejar sin efecto actuaciones solo exigiendo que el impedimento no sea imputable al litigante afectado, sin requerir defecto procesal alguno. Actuaciones perfectas pueden devenir en ineficaces como una forma de privilegiar la efectiva posibilidad de defensa de una parte por sobre la eficacia del proceso. Aunque la ley no es expresa en ese punto, acá se debe hacer un análisis de si hay perjuicio reparable por la vía de la nulidad, aun sin haber defecto ${ }^{33}$. Nótese, con todo, que si bien la jurisprudencia y la doctrina emplean el término "nulidad" ${ }^{34}$, el Código, bebiendo de su influencia española y civilista, se refiere a la rescisión ${ }^{35}$.

La segunda categoría es una excepción más aparente que real y se refiere a la casación en el fondo. En virtud de ella, es posible declarar la nulidad de una sentencia, aun cuando fuere procesalmente válida, por su falta de corrección jurídica, siempre que haya una infracción de ley que haya influido sustancialmente en lo dispositivo del fallo (artículo 767 CPC.). Aquí estamos también frente a ineficacia sin invalidez. Esto se explica porque se trata de un caso en el que, en realidad, aquello que normalmente se estudia dentro de lo que se denomina teoría de la nulidad procesal no resulta relevante. Es un tema de corrección jurídica de actos perfectamente válidos en el que se

${ }^{33} \mathrm{El}$ que no requiera de un defecto procesal no supone que no pueda haberlo. Tan así es el tema que, en el caso del incidente del artículo 80, incluso sirve para corregir defectos en el emplazamiento del demandado, cuestión que Romero SEguel, La cosa juzgada en el proceso chileno (reimpresión, Santiago, Editorial Jurídica, Santiago, 2011), p 38, considera una hipótesis de inexistencia.

${ }^{34}$ Así, por ejemplo: Otero Lathrop, M., La nulidad procesal, cit. (n. 12), p. 53, las reconoce como casos de nulidad sin vicio.

${ }^{35}$ En el ordenamiento español existe una acción de rescisión que puede oponer el litigante rebelde, que permite la revisión de la obrado (hoy está en los artículos 501 a 508 LEC., antes estuvo en los artículo 773 a 789 LEC.1881), en determinadas circunstancias, bastante similares a la de nuestros artículos 79 y 80 CPC. La diferencia es que no hay propiamente ineficacia de las actuaciones anteriores, sino una posibilidad de revisión de estas en aras a que el rebelde por motivos que no le son imputables pueda ejercer su derecho a la defensa. 
emplea la nulidad como una técnica para hacer ineficaz los actos, pero sin requerir invalidez alguna ${ }^{36}$.

Explicado tal y como se ha hecho, se debiese imponer la conclusión que en cuanto un acto procesal no perjudique a las partes es absolutamente irrelevante el nivel de separación que exista entre este y el modelo procesal de referencia. Dicho de otra manera, que las formas procesales serían completamente fungibles al poder ser todas reemplazadas -o derechamente omitidas- siempre que no se afecte a alguna de las partes.

Si bien a priori se podría hablar de algo así como un principio de fungibilidad de las formas ${ }^{37}$, el asunto parece tener algunos límites que impedirían que cualquier acto pudiese ser reemplazarlo por otro dentro de un procedimiento, por el solo hecho de cumplir con la misma función. No se debe olvidar que las formas procesales son garantías y que, en tanto tales, las partes tienen derecho a que las cosas se hagan de la manera como la ley dice que se hagan, que es la que, en abstracto, más seguridades ofrece ${ }^{38}$. Aunque ello no puede llevar a la exigencia a ultranza de la perfección de todos los actos, sí debe, al menos, excluir la posibilidad de que se realicen actos por equivalencia en las situaciones más relevantes, como las comunicaciones procesales.

Sobre el punto, Giovanardi postula la existencia de una exigencia implícita de que el acto concreto tenga al menos la fisonomía del acto correspondiente al modelo legal. A partir de esta postura, se permitiría considerar que es susceptible de reconocérsele validez al acto procesal defectuoso, pero no al simple cumplimiento por equivalencia realizado a través de un acto completamente distinto, que se ha considerado por su autor igualmente idóneo para el cumplimiento de la finalidad buscada ${ }^{39}$. Esta conclusión parece confirmada

${ }^{36}$ En definitiva, esto viene a demostrar que la invalidez y la ineficacia tienen una relación solo contingente. Prueba de ello son situaciones como las de la caducidad de las medidas cautelares ( 280 y 302 CPC.) o el acogimiento de una apelación en el solo efecto devolutivo. En ellas, sin necesidad de una declaración judicial expresa, quedan sin efecto ipso iure, respectivamente, la medida cautelar y lo actuado en virtud de la resolución de la resolución revocada. En estos casos no hay invalidez, y ni siquiera debiese hablarse de nulidad, sino solamente de ineficacia, no siendo aplicables, por ejemplo, las reglas de la nulidad procesal relativas a la convalidación o trascendencia. Una opinión distinta acerca de este punto sostiene TAVOLARI, La nulidad procesal en el derecho actual, en El proceso en acción (Santiago, Libromar, 2000), pp. 267 ss., quien reconoce a estos casos como hipótesis de nulidades de pleno derecho.

${ }^{37}$ Término empleado por BEDAQUE, J. d .S., Efectividad del proceso y técnica procesal (ci. (n. 6), p. 162.

${ }^{38} \mathrm{Al}$ menos respecto de las comunicaciones procesales, así lo plantean Ramos MÉndez, F., El sistema procesal español (7ª edición, Atelier, Barcelona, 2005), p. 287; YÉLAmos BAYARRI, E., Nulidad procesal y comunicaciones judiciales fallidas (Barcelona, Atelier, 2006), p. 448.

${ }^{39}$ Giovanardi, C. A., Sullo scopo dell atto processuale, in relazione alla disciplina della nullità, en Rivista di Diritto Civile, 2 (1987), p. 279. 
por el texto del artículo $83 \mathrm{CPC}$, pues habla de "vicio" que implícitamente refiere a un acto que tiene cierta fisonomía, pero que no cumple con todo lo exigido por el ordenamiento.

\section{Consiste en la privación de derechos particulares.}

Aunque pueda resultar un punto de partida demasiado obvio, conviene comenzar por precisar que el perjuicio debe darse en la esfera de derechos de los litigantes. No cabe aplicar esta noción al proceso, a la administración de justicia ni nada que dé un matiz de interés público a esta causal, que es eminentemente privada. Son expresos sobre el punto el artículo 83 CPC cuando se refiere a "un vicio que irrogue a alguna de las partes un perjuicio [...]” y el inciso penúltimo del artículo 768 al decir que el tribunal podrá desestimar el recurso cuando aparezca de manifiesto que "el recurrente no ha sufrido perjuicio reparable solo con la invalidación del fallo [...]”"40.

Más allá de lo anterior, la definición de qué constituye propiamente un perjuicio es algo que ha concitado poca atención en nuestra doctrina. Nuestra jurisprudencia, por su parte, tampoco ha reflexionado mucho, limitándose en cada caso a decir si lo hay o no, sin siquiera explicar cómo se produce. Esa deficiencia es especialmente reprochable en el caso de esta última, pues se trata de un concepto jurídico indeterminado, en el que la labor de determinación de su contenido debiese ser eminentemente judicial, con modulaciones que consideren las particularidades del caso concreto.

Como en cualquier concepto jurídico indeterminado, se puede reconocer en la noción estudiada núcleo de certeza y una zona de penumbra. No cabe duda que en el núcleo de la noción de perjuicio se encuentran las garantías constitucionales de carácter procesal. Dentro de ellas, la que se suele identificar más fácilmente es el derecho de defensa ${ }^{41}$, en todas sus expresiones (bilateralidad de la audiencia, derecho a la defensa letrada, derecho a la prueba, etc.). Sin embargo, para determinar si hay afectación de garantías de esta especie hay que tener presente que, en caso alguno, ellas se agotan en aquellas que expresamente se han establecido en el artículo $19 \mathrm{CPol} .{ }^{42}$,

${ }^{40}$ La noción de litigante incluye también a los terceros procesales, respecto de los cuales solo es discutible la situación del tercero excluyente que reclama la nulidad por defectos ocurridos antes de su comparecencia en el juicio, por la condición que pone el artículo 22 CPC. de respetar todo lo obrado en el juicio antes de su presentación. Sobre esta situación, véase TAVOLARI, La nulidad procesal en el derecho actual, cit. (n. 36), p. 274.

${ }^{41}$ Couture, E., Fundamentos, cit. (n. 10), p. 317; Colombo Campbell, J., Los actos procesales, cit. (n. 32), II, p. 466; OTERo LATHROP, M., La nulidad procesal, cit. (n. 12), p. 64; Carrasco Poblete, J., La nulidad procesal, cit. (n. 13), p. 75.

${ }^{42}$ En especial, en los números 3 y 7 , aunque este último con más relevancia en el proceso penal 
sino que deben entenderse incorporadas aquellas que caben dentro de las nociones de tutela judicial efectiva y de debido proceso que nuestra jurisprudencia constitucional reconoce en el numeral tercero, en especial en su inciso primero y en la noción de "racional y justo procedimiento" de su hoy inciso sexto ${ }^{43}$. En virtud de ellas, la infracción a derechos como el acceso al proceso, la imparcialidad del juez o la motivación de las sentencias perfectamente pueden fundar una declaración de nulidad ${ }^{44}$.

La identificación entre el perjuicio y garantías constitucionalizadas parece ser el criterio que sigue el Proyecto de nuevo código. En lo que se propone como su artículo 118, y bajo el epígrafe de "Trascendencia" se dice que "se entenderá existir perjuicio cuando la inobservancia de las formas o exigencias legales haya impedido a alguna de las partes ejercer sus derechos en el procedimiento, afectando su garantía a un debido proceso u ocasionando indefensión".

Considerar que el perjuicio se agota en la esfera constitucional de derechos es un riesgo propio del fenómeno de la constitucionalización del derecho procesal. Producto de la vitalización de las garantías de rango constitucional, a veces parece que no hay más que lo establecidos a nivel de la carta fundamental, dejando a los derechos no constitucionalizados casi como inexistentes ${ }^{45}$. Esto es claramente erróneo, al menos desde la perspectiva de una noción como la de perjuicio que, si bien debe incluir a los derechos de rango constitucional, no tiene por qué agotarse en ellos. Bastaría con identificar con precisión un derecho de rango legal del que se pueda ver privado una parte para que la exigencia se deba entender cumplida, sin necesidad siquiera de razonar acerca de la relevancia constitucional de ella. Este es el criterio que, aparentemente, se emplea en el procedimiento de familia. El artículo 25 de la Ley $\mathrm{N}^{\circ} 19.968$, relativo a la nulidad procesal, dice que "Se entenderá que existe perjuicio cuando el vicio hubiere impedido el ejercicio de derechos por el litigante que reclama".

Es posible ir, incluso, más allá y sostener que la afectación puede ser en derechos no solo procesales, sino también sustanciales. Es decir, que el perjuicio

${ }^{43}$ Sobre la relación entre ambos conceptos en la jurisprudencia constitucional, véase: Bordalí Salamanca, A., Análisis critico de la jurisprudencia del Tribunal Constitucional sobre el derecho a la tutela judicial, en Revista Chilena de Derecho, 38 (2011) 2, pp. 319 ss.

${ }^{44}$ En un sentido similar, De la Fuente Hernández, N., De los incidentes y de la nulidad procesal, cit. (n. 12), p. 62, identifica al perjuicio con la noción de debido proceso.

${ }^{45}$ Así lo advierte Díez-Picazo Giménez, I. en Borrajo Iniesta, I. - DíezPicazo Giménez, I. - Fernández Farreres, G., El derecho a la tutela judicial y el recurso de amparo: una reflexión sobre la jurisprudencia constitucional (Madrid, Civitas, 1995), p. 114. 
puede configurarse aun cuando formalmente los derechos procesales de las partes queden intactos, si es que con la actuación defectuosa se produce una privación que altere las pretensiones que el litigante legítimamente podría haber ejercido como planteamiento de fondo en el juicio. Pienso, en especial, en el tema de la prescripción, en donde una notificación defectuosa, hecha sobre el momento de vencimiento del plazo, puede terminar por privar al demandado de su posibilidad de alegarla ${ }^{46}$.

No hay motivo alguno para excluir a esta último rubro del ámbito de protección, porque no tiene sentido, ni es justo poner de cargo de la parte afectada -que no ha generado el acto ni ha concurrido a su materializaciónlas consecuencias del actuar defectuoso de otros, sea del tribunal o de la contraparte. Cualquier limitación del concepto de perjuicio supone hacer admisible que el litigante diligente cargue con las consecuencias del comportamiento del negligente, genera un muy perverso incentivo en el sentido de que puede resultar más beneficioso hacer las cosas mal que bien y olvida que, en definitiva, el objetivo de la nulidad es dejar al litigante afectado indemne, como si no hubiese sufrido menoscabo alguno ${ }^{47}$.

4. Requiere de un perjuicio preciso y efectivo, que no necesariamente se identifica con una influencia en lo dispositivo del fallo.

Tanto el artículo 83 como el artículo 768 CPC. exigen un perjuicio efectivo para que pueda considerarse que existe nulidad ${ }^{48}$. No bastaría, entonces, la mera apreciación de una posibilidad de afectación en la esfera de derechos del reclamante para tener por inválido al acto, sino que será necesario alegar y acreditar la existencia de un perjuicio real, sea procesal o sustancial que justifique la nulidad que se pide. En este orden de ideas, no basta la sola especulación acerca de un perjuicio probable para que la nulidad proceda.

${ }^{46}$ Imagínese el siguiente caso: se presenta una demanda a pocos días de que prescriba la acción respectiva. Sabido es que nuestra jurisprudencia estima que la prescripción se interrumpe con la notificación de la demanda y no con su sola interposición. Si, ex profeso, se notificara esa demanda directamente por cédula en vez de personalmente, sin cumplir con los requisitos del artículo 44 CPC., ¿habría nulidad? Si se considera que el perjuicio es solo procesal, sería suficiente con analizar si el demandado se ha enterado oportunamente de la demanda y si ha podido ejercer, en consecuencia, el derecho de defensa. Por el contrario, si se extiende el criterio a cuestiones sustanciales, perfectamente se podría admitir la nulidad, haciendo operar la notificación en los términos del artículo 55, inciso $2^{\circ} \mathrm{CPC}$. y dándole la posibilidad, en consecuencia, de alegar la prescripción.

${ }^{47}$ En un sentido similar: GANDUlfo Ramírez, E., La aplicación del principio "venire contra factum proprium non valet": un caso de vulgarismo juridico, en Revista Chilena de Derecho, 32 (2005) 2, p. 371.

${ }^{48}$ Otero Lathrop, M., La nulidad procesal, cit. (n. 12), p. 99. 
La apreciación de un perjuicio efectivo exige la identificación precisa de él. Afirmaciones genéricas de afectación del derecho de defensa o de otro derecho no resulta una forma idónea de alegar la nulidad, pues impedirá que el sentenciador pueda efectivamente analizar el aspecto afectado ${ }^{49}$. Esto es especialmente relevante cuando estamos en el ámbito de lo convalidable en el que el silencio del legitimado para pedir la nulidad produce la validación del acto, debido a que no se podrían valorar perjuicios no reclamados.

Esta exigencia no debe confundirse con que se deba demostrar que sin el defecto procesal la decisión jurisdiccional hubiese sido distinta o, en los términos del mismo artículo 768 CPC., que el vicio haya influido en lo sustantivo del fallo. Al menos en su faz procesal, el perjuicio no tiene que ver con el resultado del juicio, sino con la valoración del camino recorrido para llegar a él, con la posibilidad de poder participar en el procedimiento que ha dado lugar a la resolución en la que puede haber influido, o no, gozando de los derechos y oportunidades que el ordenamiento procesal concede a los litigantes ${ }^{50}$. Evidentemente, si se llega a la conclusión que lo fallado hubiese sido distinto de no haber existido el defecto que se reclama, habrá un inmejorable indicio de que ha existido un perjuicio jurídicamente relevante, pero no al contrario.

De la forma planteada, a primera vista no parecería redundante la alternativa que da el artículo 768 CPC. de desestimar el recurso de casación en la forma por falta de perjuicio o por no afectar lo dispositivo del fallo ${ }^{51}$. Incluso, desde la perspectiva de la economía procesal, puede resultar razonable evitar dictar nuevos fallos si la resolución va a ser la misma.

Sin embargo, si bien no es redundante, en el contexto de las causales del ya mencionado artículo, esta limitación tiene muy poca relevancia práctica. Para que fuera relevante tendría que darse un caso que se pueda encauzar en una causal del artículo 768 CPC. en el que haya perjuicio, pero se pueda razonablemente sostener que este no ha influido en lo dispositivo del fallo, porque si concurriera también la ausencia de perjuicio, sería indistinto si existe otra limitación a la casación que cumpla la misma función ${ }^{52}$.

${ }^{49}$ Expresión de ello se puede ver en el artículo 772, inciso final, que exige al escrito del recurso de casación en la forma la mención expresa del "vicio o defecto en que se funda"

${ }^{50}$ Ramos Méndez, F., El sistema procesal español, cit. (n. 38), p. 401; YÉLAmos BAYARri, E., Nulidad procesal, cit. (n. 39), p. 250

${ }^{51}$ En contra: TAVOLARI Oliveros, R., Recursos de casación y queja: nuevo régimen (Santiago, ConoSur, 1996), p. 64.

${ }^{52}$ Artículo 768, inciso $1^{\circ}$ : "El recurso de casación en la forma ha de fundarse precisamente en alguna de las causas siguientes:/ $1^{\text {a }}$. En haber sido la sentencia pronunciada por un tribunal incompetente o integrado en contravención a lo dispuesto por la ley;/ $2^{\mathrm{a}}$. En haber sido pronunciada por un juez, o con la concurrencia de un juez legalmente implica- 
La irrelevancia queda patente a partir de lo siguiente:

a) Es claro que el juez no puede hacer una proyección de lo que no ocurrió, imaginando cómo hubiese sido aquello que no existe para determinar si podría o no haber afectado el resultado del juicio, sino que debe limitarse a constatar esto solo con los antecedentes que tiene. ¿Cómo saber, por ejemplo, qué habría pasado si el demandado se hubiese defendido o si hubiese rendido una determinada prueba? Es por ello que habría que descartar que pueda darse la limitación de no influir en lo sustancial del fallo en aquellas hipótesis que producen reenvío (números 1, 2, 3, 8 y 9), pues si hay algo que desandar del procedimiento, la proyección ya explicada no da certeza suficiente para determinar que el resultado del juicio no cambiará, por falta de información;

b) De las causales que permiten la dictación de una sentencia de reemplazo, la ultra petita, la cosa juzgada y las decisiones contradictorias, por sus características, dicen relación con la parte dispositiva del fallo, por lo que su concurrencia necesariamente implicará un cambio en lo resuelto y la consiguiente imposibilidad de que se dé la hipótesis de que el defecto no haya afectado lo dispositivo del fallo;

c) Quedaría solo la causal del número 5 del artículo en cuestión, relativa a la exigencia para las sentencias definitivas de cumplir con el contenido que les impone el inciso $1^{\circ}$ del artículo 170 del mismo Código. De ellas, es difícil imaginar que defectos en la parte expositiva (artículo 170 , inciso $1^{\circ}$, números 1,2 y 3 ) afecten lo dispositivo del fallo, pero, en la misma medida, que provoquen un perjuicio reparable solo por la declaración de nulidad. Por su parte, si el defecto está en la parte dispositiva $\left(\mathrm{N}^{\circ} 6\right)$ hay que descartarlo porque, evidentemente, influirá en aquella parte.

d) Restarían solo las infracciones relativas a las exigencias de la parte considerativa de la sentencia (números 4 y 5 del inciso primero del artículo 170 CPC.). En ellas se podría configurar un perjuicio que no afecte lo dispo-

do, o cuya recusación estépendiente o haya sido declarada por tribunal competente; / 3 a . En haber sido acordada en los tribunales colegiados por menor número de votos o pronunciada por menor número de jueces que el requerido por la ley o con la concurrencia de jueces que no asistieron a la vista de la causa, y viceversa; $4^{a}$. En haber sido dada ultra petita, esto es, otorgando más de lo pedido por las partes, o extendiéndola a puntos no sometidos a la decisión del tribunal, sin perjuicio de la facultad que este tenga para fallar de oficio en los casos determinados por la ley; / 5a. En haber sido pronunciada con omisión de cualquiera de los requisitos enumerados en el artículo 170;/ 6a. En haber sido dada contra otra pasada en autoridad de cosa juzgada, siempre que esta se haya alegado oportunamente en el juicio; / 7a. En contener decisiones contradictorias; / 8a. En haber sido dada en apelación legalmente declarada desierta, prescrita o desistida, y/ 9a. En haberse faltado a algún trámite o diligencia declarados esenciales por la ley o a cualquier otro requisito por cuyo defecto las leyes prevengan expresamente que hay nulidad". 
sitivo del fallo, si el tribunal que conoce del recurso llega a estar de acuerdo con la decisión, pero considera insuficiente la motivación que le antecede ${ }^{53}$. Hay, sin embargo, dos problemas: i) que el derecho a la motivación de la sentencia tiene valor autónomo, por lo que su sola falta o insuficiencia constituye una privación de un derecho constitucional a los litigantes, por lo que no resulta tolerable que una sentencia carezca de ella ${ }^{54}$; y ii) que el

${ }^{53}$ Es el criterio que sigue la sentencia de la Corte Suprema, rol N ${ }^{\circ}$ 661-2008 al sostener en el considerando $5^{\circ}$ : "Si bien la prueba pericial no aparece debidamente analizadas conforme lo exige la ley; es del caso señalar que el recurso de casación en la forma, como remedio de nulidad, exige como ocurre con todas las nulidades de carácter procesal que se cumpla con el principio de trascendencia, como se infiere de lo indicado en el inciso primero del artículo 83 del Código de Procedimiento Civil, en cuanto estatuye que la nulidad deberá declararse en todos aquellos casos en que exista un vicio que irrogue a alguna de las partes un perjuicio reparable solo con la declaración de nulidad. En el mismo sentido hay que entender lo que se regula en el penúltimo inciso del artículo 768 del código aludido, puesto que tratándose del recurso de casación en la forma se dispone, que no obstante lo alli dispuesto, el tribunal podrá desestimar este recurso cuando el vicio no ha influido en lo dispositivo del fallo. En este caso, es evidente que si se acepta el defecto formal que se denuncia, se debería anular la sentencia y luego, dictar otra de reemplazo que resolviera lo contrario de lo que determinó el fallo casado, pero si la decisión que habrá de dictarse en vez de la anulada llega a la misma conclusión, o sea, rechazar la demanda, es evidente que el vicio producido no influye en lo decisivo de la sentencia recurrida y por esta sola razón, como lo permite el precepto del articulo 768 referido, esta Corte no está en la obligación de invalidar ese fallo [...]".

${ }^{54}$ Así lo ha considerado el Tribunal Constitucional en la sentencia de 22 de junio de 2010, rol N 1.373-09-INA, considerando 15: "Que, en armonia con lo relacionado, puede concluirse que la motivación de la sentencia es connatural a la jurisdicción y fundamento indispensable para su ejercicio. Constituye, a la vez que un deber del juzgador, un derecho para el justiciable. Es inherente al derecho a la acción y, por ende, a la concreción de la tutela judicial efectiva; elementos propios de las garantías de un procedimiento racional y justo, cuya ausencia o limitación vulnera la exigencia constitucional'. Este criterio es también de la misma Corte Suprema. El mayor uso que hace ella de la facultad de la casación de oficio del artículo 775 CPC. va por insuficiencia en la fundamentación de esta. En una sentencia de 28 de junio de 2011, en la causa rol $N^{\circ} 807-2010$, ha dicho en su considerando 40: "Los tribunales y la doctrina han hecho hincapié en esta obligación de motivar ofundamentar las sentencias, por cuanto tal exigencia no solo dice relación con un asunto exclusivamente procesal, referido a la posibilidad de recurrir, que implica impugnar una resolución de manera de evitar errores y arbitrariedades-derecho consagrado en la Carta Fundamental, que importa la idea del racional, justo y debido proceso que debe alcanzarse en la sentencia- sino porque, además, se relaciona con un tema externo a la procesabilidad indicada, que se enmarca en la necesidad de someter al examen que puede hacer cualquier ciudadano de lo manifestado por el juez y que hace posible, asimismo, el convencimiento de las partes en el pleito, evitando la impresión de arbitrariedad al tomar estas conocimiento del porqué de una determinación". 
defecto podría perfectamente subsanarse sin la declaración de nulidad, a través de completar el fallo.

En pocas palabras, pueden haber afectaciones que incumplan el estándar de validez y que no afecten lo dispositivo del fallo, pues no hay identificación entre una figura y otra. Este análisis será especialmente relevante al momento de valorar una nulidad procesal en el contexto de un incidente, pues no es límite autónomo para él la influencia en la decisión, como sí lo es en la casación en la forma. Respecto de esta última, la no afectación de lo dispositivo del fallo es un parámetro diverso del perjuicio que, sin embargo, tiene poca relevancia práctica, porque dentro de las causales de casación en la forma es improbable encontrar defectos que generen un perjuicio sólo reparable con la anulación del fallo en situaciones que, a la vez, permitan sostener con un nivel de certeza razonable que este defecto no ha afectado lo dispositivo de él.

\section{Deja a la nulidad como ultima "ratio".}

Para que se esté frente a un acto susceptible de ser anulado, no basta con que exista un perjuicio a alguna parte, en los términos que se ha venido describiendo. Es necesario, además, que el sistema no encuentre otra salida diferente a la ineficacia del acto para que el mismo pueda ser declarado nulo ${ }^{55}$. Y es que producto de lo traumático que resulta para el proceso la ineficacia de actos, en especial cuando ella supone, además, la retroacción de las actuaciones, cualquier técnica es preferente a la de la nulidad. Esto es lo que quiere trasmitir nuestro $\mathrm{CPC}$ cuando habla de un perjuicio reparable solo por la declaración de la nulidad. Que la nulidad sea considerada el último recurso al que recurrir para eliminar un acto inválido supone dar un lugar preferente a dos técnicas a las que no siempre se les da su justo lugar: la subsanación y la convalidación.

a) Subsanación. Se debe entender por subsanación a la integración o corrección de un acto defectuoso, en general, pero no exclusivamente, por el autor de este. Sin perjuicio de algunas situaciones puntuales (como, por ejemplo, el artículo 318 CPC., referente a las excepciones dilatorias), en general, el Código no hace referencia a ella. Su aplicación preferente viene dada por la exigencia de agotar otros medios alternativos a la nulidad de los artículo 83 , inciso primero, y 768 , inciso $3^{\circ}$, pero también por la obligación que tiene el tribunal de tomar las medidas para evitar la nulidad del procedimiento (artículo 84 CPC., inciso final). Esta normas deben llevar a la conclusión que antes de decretar cualquier nulidad el tribunal debiese promover la subsanación de las actuaciones, sea llevándola a cabo por sí o requiriendo la

${ }^{55}$ Otero Lathrop, M., La nulidad procesal, cit. (n. 12), p. 65. 
corrección, procediendo la nulidad solo a falta de subsanación o frente a la imposibilidad jurídica o material de ella.

Aunque la aplicación de la subsanación no ha sido llevada aún a los límites que corresponden, un recurrente ejemplo jurisprudencial de la preferencia de ella por sobre la nulidad se da en el caso de la casación en la forma con apelación subsidiaria. En ese contexto, y con buen criterio, es común que nuestras cortes de apelaciones prefieran corregir los defectos denunciados por medio de la apelación en vez de anular el acto $^{56}$.

b) Convalidación. Por su parte, la convalidación, entendida como la aceptación de los efectos perjudiciales de un acto por parte de quien puede impetrar su nulidad ${ }^{57}$, sí goza de un estatus algo más generoso. Tradicionalmente, se distingue entre la convalidación expresa y tácita, diferenciándose en esta última entre la que se produce por el solo transcurso del plazo ( 5 días, en el caso del artículo 83) de la que se produce por la realización de cualquier actuación que no sea alegar la nulidad ${ }^{58}$. Aunque de la lectura del encabezado del artículo 83 se podría pensar que cumple un papel prácticamente irrelevante, por la aparente posibilidad de decretar la nulidad de oficio en cada caso en que haya perjuicio, al menos a nivel de doctrina no hay dudas en que la convalidación goza de preferencia y que solo son susceptibles de declararse nulos de oficio los defectos no convalidables ${ }^{59}$.

Si bien existe una mayor conciencia acerca de su prevalencia por sobre la nulidad, sus límites no siempre son completamente entendidos, en especial en lo que dice relación con la llamada casación de oficio (775 CPC.). Como si esta no fuera una forma de decretar de oficio la nulidad procesal, nuestros tribunales muchas veces olvidan el principio de que lo convalidable no es

${ }^{56}$ Un ejemplo de ello lo ofrece la sentencia de la Corte de Apelaciones de La Serena, de 4 de agosto de 2009 , causa rol $N^{\circ} 548-2008$, considerando $2^{\circ}$, frente a un caso en el que se estimó haber ultrapetita, la casación en la forma fue destinada con el siguiente argumento: "Que una atenta lectura del fallo que se cuestiona, se advierte la efectividad de lo expuesto por el recurrente resultando cierto que el juez a quo condenó a la demandada al pago de rentas de arrendamiento no demandadas. Sin embargo, no habiéndosele causado perjuicio reparable solo con la declaración de nulidad, en la medida que se interpuso recurso de apelación, amparado en los mismos y otros argumentos, de acuerdo a lo prescrito en el penúltimo inciso del artículo 768 del Código de Procedimiento Civil, se rechazará el recurso de casación en la forma que interpuso la parte demandada".

${ }^{57}$ Morón Palomino, M., La nulidad en el proceso civil español (Barcelona, Ahr, 1957), p. 208; TAVOlari, La nulidad procesal, cit. (n. 36), p. 255; Otero LATHrop, M., La nulidad procesal, cit. (n. 12), p. 62.

${ }^{58}$ Salas Vivaldi, J., Los incidentes, cit. (n. 12), pp. 92-93; Otero Lathrop, M., La nulidad procesal, cit. (n. 12), p. 62.

${ }^{59}$ Tavolari, La nulidad procesal, cit. (n. 36), pp. 254 ss.; Salas Vivaldi, J., Los incidentes, cit. (n. 12), p. 123. 
susceptible de ser anulado y se declara la nulidad de oficio de defectos claramente convalidados por las partes ${ }^{60}$.

\section{Nulidades SIN PERJUicio}

Eso de que no hay nulidad sin perjuicio (o "pas de nullité sans grief”), si bien puede ser descrita como la regla en nuestro derecho, tiene excepciones. No debe olvidarse, reitero, que el artículo 83 CPC. establece dos grandes hipótesis de nulidad: $i$ ) cuando la ley expresamente contempla la nulidad; y ii) cuando, sin contemplarse expresamente ella, hay un vicio que irrogue a alguna de las partes un perjuicio solo reparable a través de la nulidad.

Hay disposiciones expresas de nulidad, por ejemplo, en los incisos finales de los artículos 61 (acerca de autorización por el funcionario competente de las actuaciones judiciales) y 112 CPC. (nulidad de lo actuado ante un tribunal incompetente). En estos casos, habrá, en principio, invalidez sin necesidad de perjuicio ${ }^{61}$. Sea porque se quiere eximir de prueba la existencia de este o porque se quiere proteger algo distinto a los derechos de las partes (como, por ejemplo, la adecuada distribución de la carga de trabajo entre tribunales), el asunto es que en este caso no es necesario analizar en el caso concreto si se ha afectado a las partes ${ }^{62}$.

La cuestión es determinar en qué casos basta la constatación de la infracción legal, sin necesidad de que exista perjuicio, para determinar que el acto es inválido y, por lo tanto, susceptible de ser anulado. Una respuesta puramente exegética debiese llevar a concluir que no se requiere de perjuicio solo en aquellos casos en los que hay disposición legal expresa, porque así lo dispone el artículo 83 CPC. Si se pone la mirada en la casación habría que

${ }^{60}$ Así, por ejemplo, la sentencia de la Corte Suprema de 19 de mayo de 2011, en la causa rol $\mathrm{N}^{\circ} 3740-2009$, que anula de oficio una sentencia por estar en contradicción de otra pasada en autoridad de cosa juzgada.

${ }^{61}$ La existencia de este tipo de invalidez es algo en lo que la doctrina ha reparado desde hace un buen tiempo. Ya Alsina, H., Las nulidades en el proceso civil, cit. (n. 11), p. 73, se refería a ellas como nulidades automáticas, que serían una excepción a la regla "pas de nullité sans grief". Más recientemente, Richard González, M., Tratamiento procesal de la nulidad de actuaciones (Pamplona, Aranzadi, 2008), p. 18, se refiere a estas situaciones como casos de nulidad objetiva, debido a que se producen de la sola comparación entre la norma procesal general y la norma específica procesal.

${ }^{62}$ Tavolari, La nulidad procesal, cit. (n. 36), p. 266, insta por la inclusión de la noción de perjuicio incluso en aquellos casos que identifica como de nulidad absoluta, agregando que "Me parece que en aquellos casos en que por razones de política legislativa se entienda inevitable la declaración de nulidad, la forma que concilie estas motivaciones será la de presumir de derecho que determinadas infracciones o vicios irrogan perjuicios". 
tener presente que todas las causales de casación en la forma del artículo 768 requieren de este elemento para su determinación, pues su inciso tercero no hace exclusión alguna en este punto.

No ha sido este, sin embargo el criterio mayoritario en nuestra doctrina. Sobre el punto, Salas Vivaldi sostiene que "la nulidad puede declararse también cuando la irregularidad que le sirve de antecedente involucra alteración grave en el ordenamiento jurídico cuya protección interesa a la sociedad"63, que serían aquellos esenciales del proceso, es decir "los presupuestos procesales indispensables para que el proceso sea un medio idóneo para resolver los juicios"64.

La postura anterior tiene alguna complejidad, pues postular algo así supone afirmar que existen causales o, al menos, estándares de nulidad que serían meramente formales de algo que sería algo así como un orden público procesal ajeno a las garantías de las partes, que permitiría declarar nulidades sin perjuicio. Eso, que era tolerable en un sistema sin regulación expresa del tema, no es admisible en uno que sí lo regula, haciendo una opción valorativa clara, como se ha dicho, por el antiformalismo.

La cuestión planteada tiene alguna proyección práctica si se analizan las causales de casación en la forma del tanta veces mencionado artículo 768 CPC. Con el criterio del perjuicio, hay casuales que prácticamente no tienen sentido, en especial respecto de los trámites calificados como esenciales en primera instancia del artículo 795. ¿Se podría, bajo el criterio del perjuicio decretar la nulidad por la falta del trámite de conciliación ${ }^{65}$ o por omitirse la citación a las partes a oír sentencia ${ }^{66}$ ? Difícilmente. Este absurdo se provoca porque en el sistema del Código quedan vestigios formalistas, como lo es un listado de trámites esenciales, que se vuelven inútiles frente a criterios que no lo son.

\section{Conclusiones}

Nuestras conclusiones son las que sigue:

$1^{\circ}$ El perjuicio reparable solo por la vía de declaración de la nulidad es el principal estándar de invalidez de los actos procesales, tanto en el proceso civil, como en el resto de los procesos hoy vigentes en nuestro país.

$2^{\circ}$ La existencia de un parámetro de esta especie se explica en el contexto

\footnotetext{
${ }^{63}$ Salas Vivaldi, J., Los incidentes, cit. (n. 12), p. 88.

${ }^{64}$ Ibíd., p. 119.

${ }^{65}$ Tavolari Oliveros, R., Recursos de casación y queja, cit. (n. 51), p. 57.

${ }^{66} \mathrm{Sin}$ mayor reflexión es lo que ocurre en la sentencia de la Corte de Apelaciones de Rancagua de 17 de octubre de 2003, rol N 19.731.
} 
de una concepción instrumental del derecho procesal en la que el principio de trascendencia se expresa como una consecuencia necesaria de ella.

$3^{\circ}$ La consideración del perjuicio es un parámetro marcadamente antiformalista, que se desarrolla a partir de la afectación que produce un defecto procesal en la esfera de derechos de las partes y no en el grado de separación entre el acto y el modelo normativo de este.

$4^{\circ} \mathrm{La}$ afectación a las partes que es valorable a efectos de la nulidad procesal es aquella que se produce a partir de un defecto procesal. En los actos realizados de forma perfecta no cabe dicha consideración, salvo que estemos frente a las situaciones excepcionales de rescisión procesal, de los artículos 79 y 80 CPC. o de la casación en el fondo, caso este último en que se emplea la nulidad como una técnica para hacer ineficaces actos procesalmente válidos pero jurídicamente incorrectos.

$5^{\circ}$ Siendo un concepto jurídico indeterminado, precisar qué constituye un perjuicio suficiente para producir nulidad es un tema que debe ser abordado a partir del caso concreto y considerando la dinámica del proceso en cuestión.

$6^{\circ}$ Con todo, es unánimemente admitido que la afectación de garantías procesales de rango constitucional cumplen con el estándar. Esta noción debe ser tomada ampliamente, incluyendo no solo la vulneración del derecho de defensa, sino también de aquellas expresiones que caben dentro de las nociones de tutela judicial efectiva y debido proceso, que se pueden desprender del artículo $19 \mathrm{~N}^{\circ} 3 \mathrm{CPol}$., en especial de sus incisos primero y sexto.

$7^{\circ}$ Fuera de ello, se propone ampliar el concepto de perjuicio a derechos procesales no constitucionalizados y, también, a derechos sustanciales, que se puedan ver afectados por la existencia de un defecto procesal.

$8^{\circ} \mathrm{El}$ perjuicio idóneo para producir la nulidad debe ser efectivo y concreto, no bastando la identificación meramente hipotética o genérica de este. Con todo, este perjuicio no necesariamente debe identificarse a partir de la influencia de este en lo dispositivo del fallo.

$9^{\circ}$ Como está diseñado, para que pueda existir nulidad no basta con que exista un perjuicio. Es también necesario que no exista otra salida distinta la ineficacia para remediarlo. Esto es lo que hace que la subsanación y la convalidación se deban considerar técnicas preferentes por sobre la nulidad y, también, la inadmisión.

$10^{\circ}$ Por último, se hace presente la existencia de nulidades sin perjuicio, que son aquellas que se pueden encontrar en los casos que la ley establece. Parece discutible que aquella noción pueda extenderse, además, a otros casos en los que se considere afectado nociones como la de orden público procesal. 


\section{BiBLIOGRAFÍA}

Alessandri Rodríguez, F., Ley N 7.760: reformas introducidas al Código de P. Civil por la ley $N^{\circ} 7.760$ (Santiago, Impr. Otero, 1944).

Almagro Nosete, J. - Tomé Paule, J., Instituciones de Derecho procesal (Madrid, Trivium, 1993), I.

Alsina, H., Las nulidades en el proceso civil (Buenos Aires, Ediciones Jurídicas EuropaAmérica, 1958).

Andrés Ciurana, B., La invalidez de las actuaciones en el proceso civil(Valencia, Tirant lo Blanch, 2005).

Bedalue, J. d. S., Efectividad del proceso y técnica procesal (traducción de Juan José Monroy Palacios y Christian Delgado Suárez, Lima, Communitas, 2010).

Bonet Navarro, Á., Rasgos de la forma y formalismo en el proceso (en defensa de la forma), en Revista de Derecho Procesal Iberoamericana, 2-3 (1977).

Bordalí Salamanca, A., Análisis crítico de la jurisprudencia del Tribunal Constitucional sobre el derecho a la tutela judicia, en Revista Chilena de Derecho, 38 (2011) 2.

Borrajo Iniesta, I. - Díez-Picazo Giménez, I. - Fernández Farreres, G., El Derecho a la tutela judicial y el recurso de amparo: una reflexión sobre la jurisprudencia constitucional (Madrid, Civitas, 1995).

Carnelutti, F., Sistema de derecho procesal civil (traducción de Niceto Alcalá-Zamora y Castillo y Santiago Sentís Melendo, Buenos Aires, UTEHA, 1944), I.

Carrasco Poblete, J., La nulidad procesal como técnica protectora de los derechos y garantias de las partes en el derecho procesal chileno, en Revista de Derecho de la Universidad Católica del Norte, 1 (2011).

Chiovenda, G., Las formas en la defensa judicial del derecho, en El mismo, Ensayos de derecho procesal, II (traducción de Santiago Sentís Melendo, Buenos Aires, Ediciones Jurídicas Europa-América, 1949).

Colombo Campbell, J., Los actos procesales (Santiago, Editorial Jurídica de Chile, 1990), II.

Couture, E., Fundamentos del derecho procesal civil (4a edición, Montevideo, B de F, 2002).

De la Fuente Hernández, N., De los incidentes y de la nulidad procesal, en Las Reformas procesales de la ley 18.705 (Cuadernos de análisis jurídico № 7, Santiago, Escuela de Derecho Universidad Diego Portales, 1988).

Dinamarco, C. R., La instrumentalidad del proceso, (traducción de Juan José Monroy Palacios, Lima, Communitas, 2009).

GANDUlfo RAmíREZ, E., La aplicación del principio 'venire contra factum proprium non valet': un caso de vulgarismo jurídico, en Revista Chilena de Derecho, 32 (2005) 2.

GiovanARDi, C. A., Sullo scopo dell atto processuale, in relazione alla disciplina della nullità, en Rivista di Diritto Civile, 2 (1987).

Goldschmidt, J., Teoría general del proceso (Barcelona, Labor, 1936).

Guasp, J., Derecho procesal civil (2a edición, Instituto de Estudios Políticos, Madrid, 1961).

HeRnÁNDEz Galilea, La nueva regulación de la nulidad procesal: el sistema de ineficacia de la LOPJ (Oviedo, Fórum 1995).

MARTín De LA LEONA, J. M., La nulidad de actuaciones en el proceso civil (2a edición, Madrid, Colex, 1996). 
Montesano, L. - Arieta, G., Diritto processuale civile (2a edición, Torino, Giappichelli, 1997), I.

Morón Palomino, M., La nulidad en el proceso civil español (Barcelona, Ahr, 1957).

Ortells Ramos, M. - Mascarell Navarro, M.J. - Cámara Ruiz, J., Introducción al derecho procesal (Cizur Menor [Navarra], Thomson-Aranzadi, 2010).

Otero Lathrop, M., Derecho procesal civil: Modificaciones a la legislación 1988-2000 (Santiago, Editorial Jurídica de Chile, 2000).

Otero Lathrop, M., La nulidad procesal civil, penal y de derecho público (Santiago, Editorial Jurídica de Chile, 2009).

Pozo Silva, N., De las nulidades procesales (Santiago, ConoSur, 2001).

Ramos Méndez, F., El sistema procesal español ( $7^{\text {a }}$ edición, Barcelona, Atelier, 2005).

Richard González, M., Tratamiento procesal de la nulidad de actuaciones (Pamplona, Aranzadi, 2008).

Romero Seguel, A., La cosa juzgada en el proceso chileno (reimpresión, Santiago, Editorial Jurídica, 2011).

Salas Vivaldi, J., Losprincipios de especificidad, convalidación, trascendencia y extensión de la nulidad procesal en la legislación chilena, en Revista de Derecho Universidad de Concepción, 151-152 (1970).

Salas Vivaldi, J., Los incidentes y en especial el de nulidad en el proceso civil, penal y laboral ( $7^{a}$ edición, Santiago, Editorial Jurídica de Chile, 2000).

Satta, S., Il formalismo nel processo, en SATta, S., Soliloqui e colloqui di un giurista (Padova, Cedam, 1968).

Tavolari Oliveros, R., Nuevo régimen de la nulidad procesal penal, en El mismo, Estudio de Derecho procesal (Valparaíso, Edeval, 1990).

Tavolari Oliveros, R., Recursos de casación y queja: nuevo régimen (Santiago, ConoSur, 1996).

TAvolari Oliveros, R., La nulidad procesal en el derecho actual, en El proceso en acción (Santiago, Libromar, Santiago, 2000).

Urrutia Salas, M, Nulidadesprocesales (Santiago, Imprenta y Encuadernación Víctor Silva, 1928).

YÉLAMOS BAYARRI, E., Nulidad procesal y comunicaciones judiciales fallidas (Barcelona, Atelier, 2006). 
